\begin{tabular}{|c|c|c|}
\hline (Si) & $\begin{array}{c}\text { Türkiye Tarımsal Araştırmalar Dergisi } \\
\text { dergipark.org.tr/tutad }\end{array}$ & $\begin{array}{l}\text { Turk J Agric Res } \\
\text { 2019, 6(2): 142-152 } \\
\text { @ TÜTAD } \\
\text { ISSN: 2148-2306 } \\
\text { e-ISSN: 2528-858X }\end{array}$ \\
\hline Bilimin Dsügunda & Araştırma Makalesi / Research Article & doi: $10.19159 /$ tutad.453465 \\
\hline
\end{tabular}

\title{
Buğday Ekim Alanlarında Sorun Oluşturan Yabancı Ot Türleri: Siirt İli Örneği
}

\author{
Mesut SIRRI* \\ Siirt Üniversitesi, Eruh Meslek Yüksekokulu, Bitkisel ve Hayvansal Üretim Bölümü, Siirt, TÜRKIYYE
}

\begin{tabular}{ll}
\hline \multicolumn{1}{c}{ Geliş Tarihi/Received: 14.08 .2018} & Kabul Tarihi/Accepted: 30.06 .2019 \\
\hline ORCID ID & \\
(Dorcid.org/0000-0001-9793-9599 & \\
"Sorumlu Yazar/Corresponding Author: m.sirri@sirt.edu.tr
\end{tabular}

*Sorumlu Yazar/Corresponding Author: m.sirri@siirt.edu.tr

Öz: Bu çalışmada, buğday ekim alanlarında sorun oluşturan yabancı otların yaygınlık durumu ve yoğunluklarının belirlenmesi hedeflenmiştir. Bu amaç doğrultusunda; Türkiye'nin Güneydoğu Anadolu Bölgesi'nde yer alan Siirt ili buğday ekili alanlarında, 2017-2018 vejetasyon döneminde (Mart-Mayıs aylarında) survey çalışmaları gerçekleştirilmiştir. Araştırmada, çalışma alanını temsil edecek şeklide rastgele toplam 84 tarlada örnekleme yapılmıştır. Surveyler sonucunda Siirt ilinde buğday tarlalarında 1'i tohumsuz, 4 monokotiledon ve 25 dikotiledon olmak üzere toplam 30 familyaya ait 137 yabanc1 ot türü tespit edilmiş̧ir. Buğday yetiştiriciliğinde önemli sorun oluşturan bu türlerin daha ziyade; Asteraceae (26 tür), Poaceae (22 tür), Fabaceae (13 tür), Brassicaceae (10 tür), Apiacecae (8 tür), Caryophyllaceae (6 tür), Eupharbiaceae (6 tür), Boraginaceae (5 tür) ve Lamiaceae (5 tür) familyalarına dâhil oldukları belirlenmiștir. Çalıșma alanında ilçeler düzeyinde yabancı otların yaygınlık ve yoğunlukları arasında kısmen farklılıklar bulunduğu saptanmıştır. Ancak yabancı otların rastlama sıklıkları ve yoğunlukları dikkate alındığında; yabani hardal (Sinapis arvensis L.), yabani yulaf (Avena spp.), gelincik (Papaver rhoeas L.), dil kanatan (Galium aparine Dandy.), tarla sarmaşı̆̆ı (Convolvulus arvensis L.), arap baklası (Vaccaria pyramidata Medik.), yonca (Medicago sativa L.) ve adi fiğ (Vicia sativa L.)'in il genelinde en fazla sorun oluşturan türler olduğu saptanmıștır. Duvar arpası (Hordeum murinum L.), saka dikeni (Carduus pycnocephalus L.), testere dişli pıtrak [Lisae astrigosa (Banksand sol.) Eig.], püsküllü çayır otu (Bromus tectorum L.), tarla düğün çiçeği (Ranunculus arvensis L.), tarla köpek papatyası (Anthemis arvensisL.), İtalyan sı̆̆ırdili (Anchusa azurea Miller.) ve adi yavşan otu (Veronica hederifolia L.) gibi bazı yabancı ot türlerinin ise yaygınlık göstermemelerine rağmen bölgesel olarak yüksek yoğunluklara ulaşabildikleri ve önemli verim kayıplarına sebep olabildikleri tespit edilmiştir. Dolayısıyla çalışma sonuçları dikkate alınarak yabancı otların idaresinde bölgeye özel yönetim stratejileri uygulanmalıdır.

Anahtar Kelimeler: Yabanc1 otlar, buğday, survey, Siirt

\section{Noxious Weed Species in Wheat Production Areas: Siirt Province Sample}

Abstract: In this study, it was aimed to determine the prevalence and density of weeds that cause problems in wheat cultivation areas. In accordance with this purpose; survey studies were conducted in the wheat fields of Siirt province, located in the Turkey's Southeastern Anatolia Region, during vegetation period (March-May) of 2017 and 2018. In this research, a total of 84 sites were randomly surveyed to represent the area. A total of 137 weed species belonging to 30 families (1 seedlees, 4 monocotyledon and 25 dicotyledon) were recorded during the surveys in the province. These most important and problematic weed species were belonged to; Asteraceae (26 species), Poaceae (22 species), Fabaceae (13 species), Brassicaceae (10 species), Apiacecae (8 species), Caryophyllaceae (6 species), Eupharbiaceae (6 species), Boraginaceae (5 species) and Lamiaceae (5 species). Slight differences were observed in the prevalence and density of weed species among the surveyed districts. However, the most noxious weed species based on prevalence and density in the province were Wild mustard (Sinapis arvensis L.), Wild oat (Avena spp.), Common poppy (Papaver rhoeas L.), Cleaver (Galium aparine Dandy.), Field bindweed (Convolvulus arvensis L.), cowcockle, (Vaccaria pyramidata Medik.), Alfalfa (Medicago sativa L.) and vetch (Vicia sativa L.) Although some weed species such as Wall barley (Hordeum murinum L.), Italian thistle (Carduus pycnocephalus L.), 
Cheatgrass (Bromus tectorum L.), Corn buttercup (Ranunculus arvensis L.), Corn chamomile (Anthemis arvensis L.), Italian alkanet (Anchusa azurea Miller.) and Ivy-leaved Speedwell (Veronica hederifolia L.), were not widespread in the region, but can reach high concentrations and have been found to cause significant yield losses. Therefore, region-specific weed management strategies should be applied by considering the results of the study.

Keywords: Weed species, wheat, survey, Siirt

\section{Giriş}

Buğday temel besin kaynaklarının başında gelen kültür bitkilerinden biri olup, dünya genelinde 220 milyon hektar alanda buğday üretimi yapılmaktadır (Anonymous, 2018). Türkiye'de ise 8 milyon hektar alanda buğday üretimi yapılmakta ve Türkiye, \% 3.5'lik pay ile dünyada ilk 10 ülke içerisinde yer almaktadır (Anonim, 2018a). Türkiye'de buğday üretimi özellikle Orta Anadolu, Doğu Anadolu ve Güneydoğu Anadolu bölgelerinde, bilhassa kurak ve yarı kurak alanlarında halkın başlıca geçim kaynağını oluşturmaktadır. İnsanlar için temel besin kaynağ1 olmasının yanında, hayvanlar için de önemli bir yem kaynağı olması nedeniyle (İnan ve Rahber, 1987; Kordali ve Zengin, 2011) buğday Türkiye'de hem ekim alanı hem de üretim miktarı bakımından kültür bitkileri içerisinde en büyük paya sahiptir (Anonim, 2018a).

Tarımsal üretimi sınırlayan faktörlerin başında bitki koruma etmenleri gelmektedir. Dünya genelinde bitki koruma etmenlerinden (zararl1, hastalık ve yabancı otlar) kaynaklanan ürün kayıplarının \% 30'un üzerine çıkabildiği belirtilmektedir (Özer ve ark., 2001). Bitki koruma etmenleri içerisinde yer alan yabancı otlar; kültür bitkisi ile besin maddesi, su, 1şık ve yer konusunda rekabete girerek verimde ve kalitede önemli kayıpların oluşmasına neden olmaktadır (Özer ve ark., 1996; Özer ve ark., 2001; Güncan, 2014; Tepe, 2014). Yabanc1 otlar diğer kültür bitkilerinde olduğu gibi buğday üretiminde de önemli verim kayıplarına neden olmaktadır. Nitekim Türkiye'de yapıla araştırmalarda yabancı otların buğday üretiminde yaklaşık olarak \% 20-30'lara varan oranlarda verim kaybına neden olduğu ve bu kayıpların bölgelere göre büyük farklılıklar gösterdiği rapor edilmiştir. Örneğin, yabancı otların meydana getirdiği zararın; Ege Bölgesi'nde \% 30 (Bilgir, 1965; Tepe, 1998), Doğu Anadolu Bölgesi'nde \% 24 (Güncan, 1975), Çukurova Bölgesi'nde ise \% 20 (Uygur ve ark., 1999; Güngör, 2005) oranında olduğu tespit edilmiştir. Dünya geneline bakıldığında; Almanya'da yabancı otlardan kaynaklanan ürün kayıpları \% $15-25$ arasında iken (Hurle, 1988), bu oran İngiltere'de \% 66'lara ulaşabilmektedir (Whitehead and Wright, 1989).
Türkiye'de buğday tarımı gerek ekolojik gerekse ekonomik anlamda önemli bir konumda olmasına rağmen, verim ve kalite açısından istenilen düzeyde değildir. Bu nedenle de ihtiyaç duyulan buğday dışarıdan satın alınmaktadır. Buğday üretiminde verim düşüşüne neden olan temel sorunların başında tohumluk temini, yetiştiricilik ile ilgili yanlış uygulamalar ve başta yabanc1 otlar olmak üzere bitki koruma etmenlerinden kaynaklanan sorunlar gelmektedir (Gökalp ve Üremiş, 2015). Türkiye'de genel olarak yabanc1 ot mücadelesinde bölgede sorun olan yabancı otlardan çok, kültür bitkisi dikkate alınarak takvime bağlı yabancı ot mücadelesi yapılmaktadır. Dolayısıyla farklı bölgelerde yabancı ot türleri dikkate alınmadan benzer mücadele uygulamaları yapılmaktadır. $\mathrm{Bu}$ durum yabanc1 otlarla mücadelede başarı oranını düşürmekte, aşırı ilaç kullanımından dolayı hem maliyetin yükselmesine neden olmakta, hem de çevre ve insan sağlığını riske sokmaktadır. Ayrıca yabancı otlarla mücadelede uygun ilaç kullanılmadığından veya sürekli aynı herbisitlerin kullanımı sonucu yabancı otların dayanıklılık kazanması vb. problemlerinin ortaya çıkmasına zemin hazırlamaktadır (Güncan, 2001; Önen ve Özer, 2001; Sırr1, 2014). Dolayısıyla buğday ekim alanlarında yabancı otların başarılı bir şekilde idare edilmesi için (arazi kullanımı, ekim nöbeti ve ekolojik faktörlere de bağlı olarak) öncelikle sorun olan yabancı ot türleri ile bunların yaygınlık ve yoğunluklarının saptanması büyük önem arz etmektedir (Önen ve Özer, 2001). Bu çalışmada; buğday ekim alanlarında yabancı ot idaresine yönelik olarak stratejilerin geliştirilmesine katkı sağlanması amacıyla, sorun oluşturan yabancı otların yaygınlık durumu ve yoğunluklarının Siirt ili özelinde belirlenerek ortaya konulması hedeflenmiştir.

\section{Materyal ve Yöntem}

\section{1. Çalışma alanının genel tanımı ve bazı coğrafik özellikleri}

Araştırma; Türkiye'nin Güneydoğu Anadolu Bölgesi'nde yer alan Siirt ili buğday ekiliş alanlarında 2017-2018 yıllarında yürütülmüş olup, Siirt ili $37^{\circ} 56^{\prime} 39^{\prime \prime}$ doğu boylamı ile $41^{\circ} 55^{\prime} 58^{\prime \prime}$ kuzey enlemleri arasında yer almaktadır. Siirt ili, hem Akdeniz iklimi hem de karasal iklimin ortak 
özelliklerini taşımakta olup; yazları çok sıcak ve kurak, kışları ise bol yağışlı ve 1lıman geçmektedir (Şekil 1) (Anonim, 2018b). Bu iklim özelliği ile Siirt'te genel olarak kışlık buğday yetiştiriciliği yapılmaktadir.

Siirt ilinin batı kesimi daha düz ve düze yakın ovalık arazilerden oluşurken, kuzeyi ve doğusunda rakım yüksektir. İlin \% 65'lik gibi büyük çoğunluğunda kahverengi orman toprağı bulunur. Siirt ilinin yaklaşık \% 90'1nda orta, şiddetli ve çok şiddetli erozyon görülmekte; I.-III. sınıf araziler il toplam alanının sadece \% 9'luk k1sminı oluşturmakta; alanın büyük bir kısmı ( $\%$ 85) çok sı̆ ve sığ topraklara sahip iken, derin ve çok derin topraklar ise buğday tarımının da ağırlıklı olduğu batı kesimindeki ovalık arazilerde yer almaktadır (Özyazıcı ve ark., 2014).

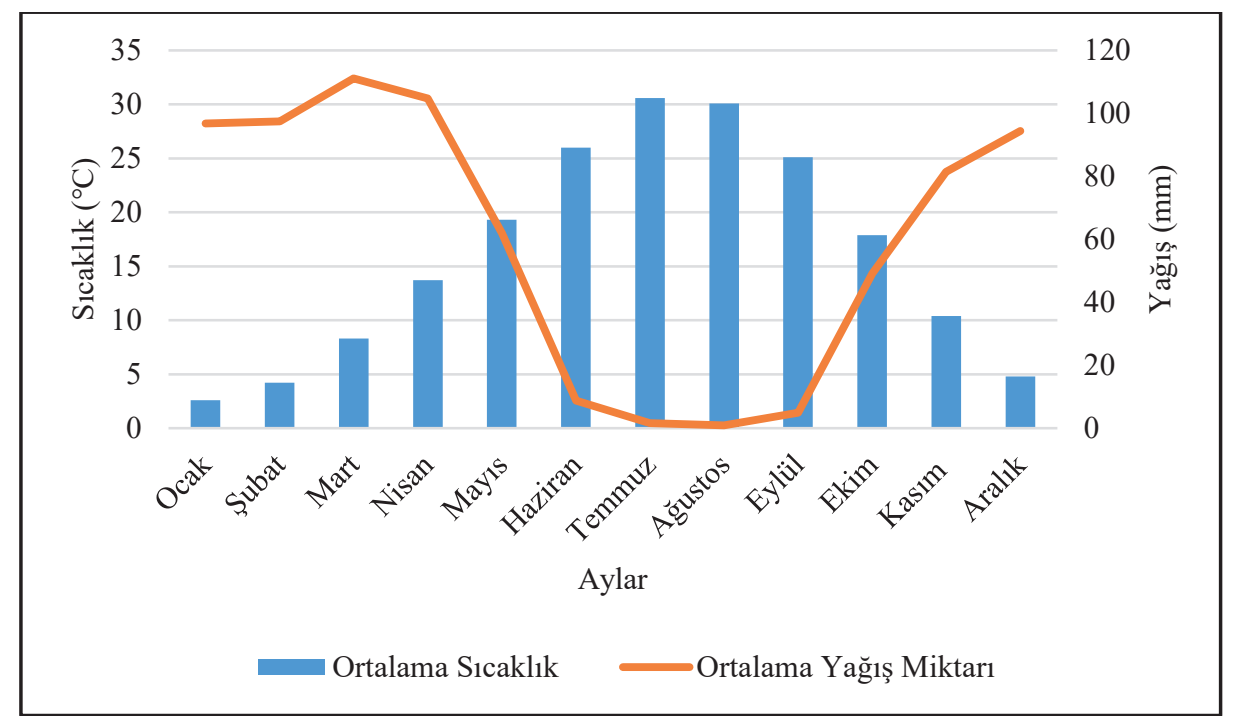

Şekil 1. Siirt iline ait uzun yıllar (1938-2017) ortalaması bazı iklim verileri

\subsection{Yabancı ot türleri ve yoğunluklarının tespiti}

Gözlem ve örnekleme işlemlerine yönelik arazi çalışmaları; buğday üretim miktarları da dikkate alınarak Siirt ilinin buğday üretimi yapılan Merkez, Kurtalan, Eruh, Pervari, Baykan, Tillo ve Şirvan ilçelerini kapsayacak şekilde gerçekleştirilmiştir. Çalışma alanında örnekleme noktalarının belirlenmesi için yaklaşık her 5 km'de bir tesadüfî olarak durulmuş ve en yakın buğday tarlasına girilmiştir. Girilen tarlalarda, kenar tesirini ortadan kaldırmak için tarla kenarından yaklaşık 10 m içeri girilerek ölçümlere başlanmıştır. Her bir tarlada tarlayı temsil edecek şekilde; 5 dekar büyüklüğüne sahip tarlalarda 5, 7-10 dekar için 7, 10 dekardan daha büyük tarlalar için 10 adet olmak üzere 0.25 $\mathrm{m}^{2}$ lik çerçeve atılarak, çerçeve içerisindeki yabanc1 otların türleri sayılmıştır (Önen, 1995). Çalışmada tespit edilen yabancı otların yoğunlukları (Y) Eşitlik 1 yardımıyla hesaplanmış, yaygınlıkları [Rastlama sıklığı (RS)] ise Eşitlik 2'ye göre belirlenmiştir (Odum, 1971).

$$
\mathrm{Y}\left(\operatorname{adet} \mathrm{m}^{-2}\right)=\mathrm{b} / \mathrm{m}
$$

Eşitlikte b, alınan örnekte toplam birey sayısını; $\mathrm{m}$, toplam örnekleme sayısını ifade etmektedir.

$$
\operatorname{RS}(\%)=100 \times \mathrm{n} / \mathrm{m}
$$

Eşitlik 2'de n, yapılan örneklemenin kaçında o tür ile karşılaşıldığını; m, toplam örnekleme sayısını ifade etmektedir.

Araştırmada, çalışma alanını temsil edilecek şekilde 2017 yılında 50, 2018 yılında ise 34 tarlada, toplamda 84 olmak üzere rastgele örnekleme yapılmıştır (Şekil 2). Arazi çalışmaları Mart-Mayıs aylarını kapsayan vejetasyon dönemlerinde gerçekleştirilmiştir.

Yabanc1 ot türlerinin teşhisleri ve isimlendirilmesinde; Davis $(1965,1989)$, Uluğ ve ark. (1993), Özer ve ark. (1998, 1999), Baytop (2007), Anonim (2018c) ve Anonim, (2019)'dan yararlanmıştır.

\section{Bulgular ve Tartışma}

Siirt ili buğday ekim alanlarında yürütülen bu çalışmada, buğday tarlalarında tespit edilen yabancı ot türleri, rastlama sıklıkları ve yoğunlukları Tablo 1 'de verilmiştir. Elde edilen bulgulara göre, genel olarak tarım alanlarında önemli sorunlara yol açan yabancı ot familyalarının bölgede dominant olduğu görülmektedir. Nitekim daha önce farkl1 araştırmacilar (Uluğ ve ark., 1993; Tepe, 1998; Özer ve ark., 1999, 2001) tarafindan tarım 


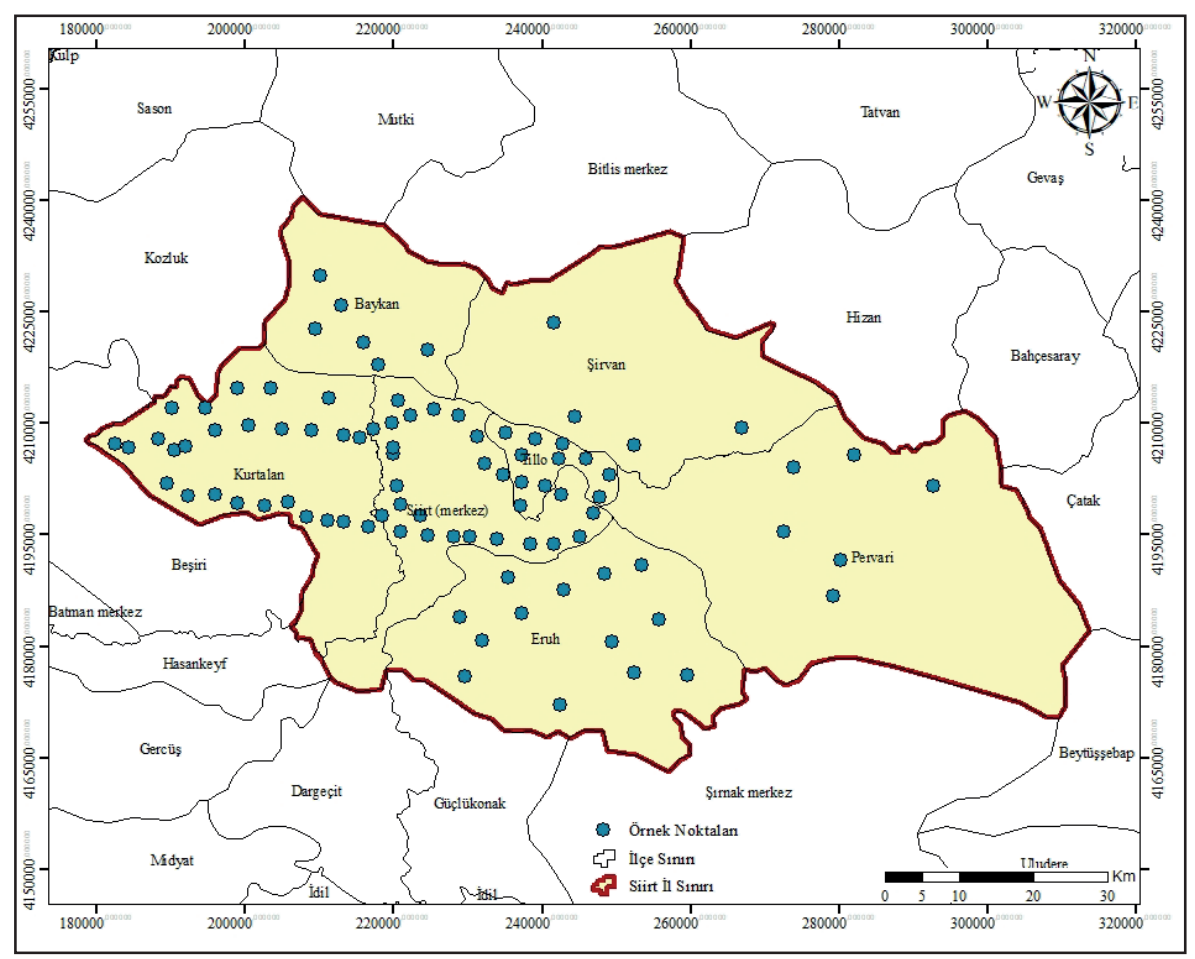

Şekil 2. Siirt ili coğrafik konum haritası ve örnekleme noktalarının dağılımı

alanlarında en yaygın görülen familyalar arasında ilk sıralarda yer aldığ 1 tespit edilen Asteraceae, Poaceae, Fabaceae ve Brassicaceae familyaları çalışma alanında da en fazla tür ile temsil edilen familyalar olmuştur (Tablo 1).

Araştırmada; 1'i tohumsuz, 4'ü monokotiledon, 25'i dikotiledon olmak üzere toplam 30 familyaya ait 137 yabanc1 ot türü saptanmıştır. Bu yabanc1 otlardan 9 türün (Silybum marianum L., Sinapis arvensis L., Vaccaria pyramidata Medik, Convolvulus arvensis L., Medicago sativa L., Papaver rhoeas L., Avena spp., Lolium perene L., Vicia sativa L. ve Galium aparine L.) rastlama sıklığının \% 50'den fazla olduğu görülmektedir. İki yıllık survey sonuçlarına göre buğday tarlalarında en fazla yoğunluk oluşturan türlerin ise; $S$. arvensis, $C$. arvensis, P. rhoeas, Avena spp., G. aparine, M. sativa, Linum spp., L. perene L., V. pyramidata, Veronica hederifolia L., Lisaea strigosa (Banks and sol.) Eig., Carduus pycnocephalus L., Centaurea iberica Trevir ex Sprengel., Anchusa azurea Miller., Thlaspi arvense L., Euphorbia helioscopia L., Agrostis stolonifera L., Bromus tectorum L. ve Anagallis arvensis L. olduğu saptanmıştır (Tablo 1). Bölgede yaygın olarak bulunan 9 yabancı ot türü aynı zamanda önemli seviyede yoğunluk oluşturduklarından çalışma alanında dominant olan yabanc1 ot türleri konumunda bulunmaktadır.

$\mathrm{Bu}$ araştırma sonuçlarına göre buğday alanlarında tespit edilen yabancı otlarda $\mathrm{m}^{2}$, $\mathrm{de}$ 1 'den fazla belirlenen yabancı otlar; $S$. arvensis
(1.59 bitki $\left.\mathrm{m}^{-2}\right)$, C. arvensis $\left(1.48\right.$ bitki $\left.\mathrm{m}^{-2}\right)$,

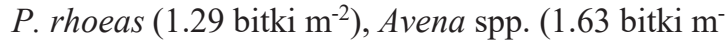
$\left.{ }^{2}\right)$, G. aparine (2.05 bitki $\mathrm{m}^{-2}$ ) ve $V$. sativa $(1.67$ bitki $\mathrm{m}^{-2}$ ) olarak saptanmıştır. Farklı ilçelerdeki buğday tarlalarında yapılan surveyler dikkate alındığında ise yabancı ot türlerinin dağılımlarında büyük bir değişikliğin olmadığı ve hemen hemen aynı türlerin yaygın ve yoğun olduğu görülmüştür (Tablo 1). Örneğin Avena spp.'nin rastlama sıklığı en fazla olan tür olurken, G. aparine türü birim alanda daha fazla bulunan yabanc1 ot olmuştur. $\mathrm{Bu}$ nedenle buğdayın tür ya da çeşidinin yabancı ot florası üzerinde çok belirgin bir etkisinin olmadığ görülmektedir.

Güneydoğu Anadolu Bölgesi'nde buğday alanlarında sorun olan yabancı otların belirlenmesine yönelik olarak literatürde yer alan iki çalışma (Uludağ ve Katkat, 1993) bulunmaktadır. Ancak Siirt ilinde buğday ekim alanlarında sorun olan yabancı otların saptanmasına yönelik yapılmış detaylı bir çalışma bulunmamaktadır. Türkiye'nin farklı ekolojilerinde buğday ekim alanlarında sorun olan yabancı otların saptanmasını hedefleyen çok sayıda çalışmalar (Güncan, 1975; Taştan ve Erciş, 1991; Mennan, 1993; Sirma, 1995; Sirma ve Güncan, 1997; Tepe, 1998; Özrenk ve Tepe, 1999; Kaya ve Zengin, 2000; Mennan ve Işık, 2003; Tursun ve ark., 2004; Karaca, 2010; Sırma ve Kadığlu, 2010; Özaslan ve ark., 2011; Önen ve ark., 2012; Söker ve ark., 2012; Sırrı, 2014; Gökalp ve Üremiş, 2015; Pala ve 
Tablo 1. Siirt buğday tarlalarında belirlenen yabancı ot türleri ve bunların rastlama sıklıkları ve yoğunlukları

\begin{tabular}{|c|c|c|c|}
\hline Bilimsel ad 1 & Yerel ad1 & RS & $\mathrm{Y}$ \\
\hline \multicolumn{4}{|c|}{ AMARANTHACEAE } \\
\hline Amaranthus retroflexus $\mathrm{L}$. & Horozibiği & 4 & 0.04 \\
\hline \multicolumn{4}{|c|}{ APIACEAE (Umbelliferae) } \\
\hline Ammi visnaga (L.) Lam. & Kürdan otu & 16 & 0.4 \\
\hline Bupleurum rotundifolium L. & Yuvarlak tavşankulağ1 & 12 & 0.3 \\
\hline Caucalis platycarpos $\mathrm{L}$. & Küçük pitrak & 17 & 0.22 \\
\hline Daucus carota $\mathrm{L}$. & Yabani havuç & 16 & 0.19 \\
\hline Echinophora tenuifolia $\mathrm{L}$. & Tarhana otu & 2 & 0.02 \\
\hline Lisaea strigosa (Banks and Sol.) Eig. & Testere dişli pıtrak & 41 & 0.98 \\
\hline Scandix pecten-veneris L. & Zühre tarağ1 & 10 & 0.15 \\
\hline Turgenia latifolia (L.) Hoffm. & Pitrak & 11 & 0.11 \\
\hline \multicolumn{4}{|c|}{ ARISTOLOCHIACEAE } \\
\hline Aristolochia maurorum L. & Loğusa otu & 25 & 0.41 \\
\hline \multicolumn{4}{|c|}{ ASTERACEAE (Compositae) } \\
\hline Achillea wilhelmsii C. Koch & Civanperçemi & 1 & 0.01 \\
\hline Acroptilon repens (L.) DC. & Kekre & 3 & 0.03 \\
\hline Anthemis arvensis $\mathrm{L}$. & Tarla köpek papatyası & 34 & 0.51 \\
\hline Anthemis tinctoria L. & Boyac1 papatyas1 & 3 & 0.09 \\
\hline Carduus pycnocephalus L. & Saka dikeni & 44 & 0.52 \\
\hline Carduus nutans $\mathrm{L}$. & Diken & 10 & 0.11 \\
\hline Centaurea depressa Bieb. & Peygamber çiçeği & 6 & 0.14 \\
\hline Centaurea solstitialis $\mathrm{L}$. & Güneş dikeni & 15 & 0.16 \\
\hline Centaurea iberica Trevir ex Sprengel. & Gelin düğmesi & 42 & 0.42 \\
\hline Chondrilla juncea $\mathrm{L}$. & Ak hindiba & 4 & 0.04 \\
\hline Cichorium intybus L. & Yabani hindiba & 5 & 0.05 \\
\hline Cirsium arvense (L.) Scop. & Köygöçüren & 21 & 0.21 \\
\hline Crepis sp. & Pis kokulu hindiba & 17 & 0.17 \\
\hline Crupina crupinastrum (Moris) Vis. & Gelin döndüren & 5 & 0.05 \\
\hline Gundelia tournefortii $\mathrm{L}$. & Kenger & 7 & 0.07 \\
\hline Echinops orientalis Trautv. & Topuz dikeni & 3 & 0.03 \\
\hline Lactuca serriola $\mathrm{L}$. & Ac1 marul & 25 & 0.25 \\
\hline Matricaria chamomilla $\mathrm{L}$. & Hakiki papatya & 1 & 0.01 \\
\hline Picnomon acarna (L.) Cass. & Pamuk dikeni & 32 & 0.32 \\
\hline Senecio vernalis Waldst and Kit. & İmam kavuğu & 1 & 0.01 \\
\hline Senecio vulgaris L. & Kanarya otu & 2 & 0.03 \\
\hline Silybum marianum (L.) Gaertner & Meryem ana dikeni & 59 & 0.6 \\
\hline Sonchus oleraceus L. & Eşek marulu & 1 & 0.01 \\
\hline Taraxacum sp. & Aslan dişi & 19 & 0.19 \\
\hline Tragopogon latifolius Boiss. & Yemlik & 15 & 0.15 \\
\hline Xanthium strumarium L. & Domuz Pitrağ 1 & 5 & 0.05 \\
\hline \multicolumn{4}{|c|}{ BERERIDACEAE } \\
\hline Bongardia chrysogonum (L.) Spach & Çatlakotu & 3 & 0.03 \\
\hline Leontica leontopetulum L. & Aslanpençesi & 8 & 0.09 \\
\hline \multicolumn{4}{|c|}{ BORAGINACEAE } \\
\hline Alkanna trichophila var. mardinensis & Havacıva otu & 1 & 0.01 \\
\hline Anchusa azurea Miller. & İtalyan sığırdili & 30 & 0.44 \\
\hline Buglossoides arvense (L.) Johnst & Taş kesen otu & 3 & 0.1 \\
\hline Echium italicum $\mathrm{L}$. & Adi engerek & 1 & 0.01 \\
\hline Onosma sp. & Altın damlası & 2 & 0.02 \\
\hline \multicolumn{4}{|c|}{ BRASSICACEAE (Cruciferae) } \\
\hline Alyssun sp. & Kuduz otu & 1 & 0.01 \\
\hline Capsella bursa-pastoris (L.) Medik. & Çobançantası & 4 & 0.08 \\
\hline Cardaria draba (L.) Desv. & Kir teresi & 29 & 0.4 \\
\hline Conringia orientalis (L.) ANDRZ. & Tavşan hardalı & 7 & 0.13 \\
\hline Descurainia sophia (L.) Webb. & Uzun süpürge otu & 7 & 0.07 \\
\hline Isatis tinctoria $\mathrm{L}$. & Çivit otu & 2 & 0.02 \\
\hline Myagrum perfoliatum $\mathrm{L}$. & Gönül hardalı & 23 & 0.23 \\
\hline Neslia apiculata Fisch. & Trakya hardalı & 20 & 0.25 \\
\hline Sinapis arvensis L. & Yabani hardal & 90 & 1.59 \\
\hline Thlaspi arvense L. & Tarla akça çiçeği & 14 & 0.41 \\
\hline
\end{tabular}

RS: Rastlama sıklığı, Y: Yoğunluk 
Tablo 1. (devami)

\begin{tabular}{|c|c|c|c|}
\hline Bilimsel ad1 & Yerel ad1 & $\mathrm{RS}$ & $\mathrm{Y}$ \\
\hline \multicolumn{4}{|c|}{ CARYOPHYLLACEAE } \\
\hline Agrostemma githago L. & Karamuk & 7 & 0.16 \\
\hline Cerastium dichotomum $\mathrm{L}$. & Boynuz otu & 9 & 0.15 \\
\hline Silene conoidea L. & Misir nakili & 4 & 0.04 \\
\hline Silene conica $\mathrm{L}$. & Yapışkan nakıl & 20 & 0.3 \\
\hline Stellaria media (L.) Vill. & Serçe dili & 8 & 0.08 \\
\hline Vaccaria pyramidata Medik & Arap baklas1 & 51 & 0.94 \\
\hline \multicolumn{4}{|c|}{ CLUSIACEAE } \\
\hline Hypericum scabrum L.(Syn. H.cymosum.H.galioides) & Kaba kuzu kıran & 4 & 0.04 \\
\hline \multicolumn{4}{|c|}{ CONVOLVULACEAE } \\
\hline Convolvulus arvensis L. & Tarla sarmaşığ1 & 66 & 1.48 \\
\hline Convolvulus galaticus Rotsan ex Choisy & Boz tarla sarmaşık & 13 & 0.27 \\
\hline \multicolumn{4}{|c|}{ DIPSACEAE } \\
\hline Cephalaria syriaca (L.) Schrad. & Uyuz otu & 14 & 0.14 \\
\hline \multicolumn{4}{|c|}{ EUPHORBIACEAE } \\
\hline Chrozophora tinctoria (L.) Rafin. & Bambul otu & 2 & 0.02 \\
\hline Euphorbia aleppica L. & Halep sütleğeni & 13 & 0.13 \\
\hline Euphorbia helioscopia L. & Güneş sütleğeni & 4 & 0.47 \\
\hline Euphorbia spp. & Sütleğen & 11 & 0.11 \\
\hline Euphorbia amygdaloides L. & Sütleğen & 11 & 0.15 \\
\hline Euphorbia serpens Kunth. & Tüysüz hanım döşeği & 1 & 0.01 \\
\hline \multicolumn{4}{|c|}{ EQUISETACEAE } \\
\hline Equisetum arvense L. & Atkuyruğu & 3 & 0.35 \\
\hline \multicolumn{4}{|c|}{ FABACEAE } \\
\hline Alhagi pseudalhagi Bieb.) Desv. & Deve dikeni & 8 & 0.08 \\
\hline Astragalus sp. & Geven & 2 & 0.02 \\
\hline Glycyrrhiza glabra L. & Meyan kökü & 10 & 0.1 \\
\hline Lathyrus sp. & Yabani mürdümük & 19 & 0.26 \\
\hline Lens culinaris Medik & Kendi gelen mercimek & 8 & 0.15 \\
\hline Medicago sativa L. & Yonca & 59 & 0.85 \\
\hline Melilotus officinalis (L.) Desr. & Sarı taş yoncası & 15 & 0.15 \\
\hline Onobrychis sp. & Korunga & 2 & 0.02 \\
\hline Pisum sativum L. & Bezelye & 2 & 0.23 \\
\hline Trifolium stellatum L. & Yıldızlı üçgül & 15 & 0.15 \\
\hline Trifolium sp. & Üçgül & 34 & 0.34 \\
\hline Trifolium pilulare Boiss. & Tüylü üçgül & 1 & 0.01 \\
\hline Vicia narbonensis L. & Kaba tüylü fiğ & 23 & 0.25 \\
\hline \multicolumn{4}{|c|}{ GERANIACEAE } \\
\hline Erodium hoefftianum C.A.Mey & Dönbaba & 7 & 0.28 \\
\hline Geranium dissectum $\mathrm{L}$. & Turnagagas 1 & 19 & 0.35 \\
\hline Geranium tuberosum L. & Devetabanı & 7 & 0.08 \\
\hline \multicolumn{4}{|c|}{ GUTTIFERAE } \\
\hline Hypericum triquetrifolium Turra. & Kantaron otu & 26 & 0.38 \\
\hline \multicolumn{4}{|c|}{ IRIDACEAE } \\
\hline Gladiolus atroviolaceus Boiss. & Karga soğanı & 11 & 0.13 \\
\hline \multicolumn{4}{|c|}{ LAMIACEAE (Labiatae) } \\
\hline Ajuca chamaepitys (L.) & Sarıçiçekli mayısıl otu & 1 & 0.01 \\
\hline Lallemantia iberica (Bieb.) Fisch.\&Mey. & İberya lalemant 1 & 4 & 0.04 \\
\hline Lamium amplexicaule L. & Ballıbaba & 9 & 0.1 \\
\hline Moluccella laevis L. & Dikensiz luken dudağ1 & 1 & 0.01 \\
\hline Salvia spp. & Adaçayı & 21 & 0.22 \\
\hline Ziziphora capitata L. & Anuk & 5 & 0.05 \\
\hline \multicolumn{4}{|c|}{ LILIACEAE } \\
\hline Linum spp. & Keten & 26 & 0.86 \\
\hline Linum pubescens Banks and sol. & Tüylü Pembe keten & 7 & 0.07 \\
\hline Muscari armeniacumleichtlin ex Baker & Arap sümbülü & 3 & 0.03 \\
\hline Ornithogalum narbonense L. & Akbaldır & 25 & 0.25 \\
\hline \multicolumn{4}{|c|}{ MALVACEAE } \\
\hline Alcea sp. & Hatim & 25 & 0.25 \\
\hline Malva neglecta Wallr. & Ebegümeci & 25 & 0.25 \\
\hline
\end{tabular}

RS: Rastlama sıklığı, Y: Yoğunluk 
Tablo 1. (devami)

\begin{tabular}{|c|c|c|c|}
\hline Bilimsel adı & Yerel ad1 & $\mathrm{RS}$ & $\mathrm{Y}$ \\
\hline \multicolumn{4}{|c|}{ PAPAVERACEAE } \\
\hline Fumaria officinalis L. & Şahtere & 15 & 0.32 \\
\hline Papaver rhoeas L. & Gelincik & 80 & 1.29 \\
\hline \multicolumn{4}{|c|}{ PLANTIGINACEAE } \\
\hline Plantago lanceolata $\mathrm{L}$. & Sinir otu & 9 & 0.09 \\
\hline \multicolumn{4}{|c|}{ POACEAE (Gramineaea) } \\
\hline Aegilops columnaris Zhukovsky & Buğday otu & 21 & 0.22 \\
\hline Aegilops cylindria Host. & Sakal otu & 8 & 0.13 \\
\hline Agropyron cristatum (L.) Gaertner & Adi otlak yarığ & 4 & 0.13 \\
\hline Agrostis stolonifera $\mathrm{L}$. & Narin tavus otu & 19 & 0.52 \\
\hline Alopecurus myosuroides Huds. & Tilkikuyruğu & 15 & 0.26 \\
\hline Avena spp. & Yabani yulaf & 73 & 3.63 \\
\hline Bromus inermis Leysser & Kılçıksız brom & 11 & 0.17 \\
\hline Bromus sterilis $\mathrm{L}$. & Kisir brom & 9 & 0.14 \\
\hline Bromus tectorum $\mathrm{L}$. & Püsküllü çayır otu & 39 & 0.59 \\
\hline Cynodon dactylon (L.) Pers. & Köpek dişi ayrığı & 1 & 0.01 \\
\hline Echinaria capitata (L.) Desf. & Diken baş çimi & 13 & 0.13 \\
\hline Hordeum sp. & Yabani arpa & 20 & 0.2 \\
\hline Hordeum murinum L. & Duvar arpası & 50 & 0.5 \\
\hline Lolium perenne $\mathrm{L}$. & İngiliz çimi & 57 & 0.75 \\
\hline Lolium multiflorum Lam. & Delice & 8 & 0.08 \\
\hline Poа аппиа L. & Salkım otu & 3 & 0.03 \\
\hline Poa bulbosa L. & Yumrulu salkım otu & 22 & 0.22 \\
\hline Phlaris bractystachys Link. & Kuşyemi & 22 & 0.28 \\
\hline Phragmites communis Trin. & Kamış & 2 & 0.13 \\
\hline Secale cereale $\mathrm{L}$. & Çavdar & 32 & 0.32 \\
\hline Seteria viridis (L.) P.Beauv. & Yeşil kirpi darı & 10 & 0.14 \\
\hline Sorghum halepense (L.) Pers. & Kanyaş & 2 & 0.02 \\
\hline \multicolumn{4}{|c|}{ POLYGONACEAE } \\
\hline Polygonum aviculare L. & Çobandeğneği & 4 & 0.1 \\
\hline Rumex crispus L. & Kıvırcik labada & 8 & 0.08 \\
\hline \multicolumn{4}{|c|}{ PRIMULACEAE } \\
\hline Anagallis arvensis $\mathrm{L}$. & Farekulağ 1 & 13 & 0.85 \\
\hline \multicolumn{4}{|c|}{ RANUNCULACEAE } \\
\hline Adonis aestivalis L. & Kandamlas1 & 7 & 0.08 \\
\hline Ranunculus arvensis L. & Tarla düğün çiçeği & 36 & 0.39 \\
\hline \multicolumn{4}{|c|}{ ROSACEAE } \\
\hline Sanguisorba minör Scop. & Çayır düğmesi & 9 & 0.09 \\
\hline \multicolumn{4}{|c|}{ RUBIACEAE } \\
\hline Asperula arvensis $\mathrm{L}$. & Tarla yapışkan ot & 11 & 0.22 \\
\hline Galium aparine $\mathrm{L}$. & Dil kanatan & 64 & 2.05 \\
\hline Galium tricornutum Dandy. & Boynuzlu yoğur otu & 2 & 0.02 \\
\hline \multicolumn{4}{|c|}{ SCROPHULARIACEAE } \\
\hline Veronica hederifolia L. & Adi yavşan otu & 32 & 1.53 \\
\hline \multicolumn{4}{|c|}{ VALERIANACEAE } \\
\hline Valarianella coronata (L.) DC. & Taçlı kuzu gevreği & 3 & 0.03 \\
\hline Valarianella vesiaria (L.) Moench. & Kedi otu & 8 & 0.08 \\
\hline
\end{tabular}

RS: Rastlama sıklı̆̆ı, Y: Yoğunluk

Mennan, 2017) yapılmıştır. Bu çalışmalara ait sonuçlar incelendiğinde, buğday alanlarında görülen yabanc1 ot türlerinin büyük oranda benzerlik gösterdiği söylenebilir. Bununla birlikte, Önen ve ark. (2018) tarafından da ifade edildiği üzere, survey çalışmalarının yapıldı̆ğ bölgelerin iklim ve coğrafi koşullarının da bir sonucu olarak, dominant türler arasında büyük farklılıkların olduğu görülmüştür.
Nitekim Doğu Anadolu Bölgesi’nde Erzincan ve Erzurum illerinde, buğday alanlarında baskın olan yabancı otların Agrostemma githago L., Caucalis platycarpos L., Vaccaria pyramidata Medik., Centaurea deprassa Bieb., Bromus sterilis L., Melampyrum arvense L., Secale cereale L., Cirsium arvense (L.) Scop., Polygonum aviculare L., Convolvulus arvensis L. olduğu belirlenirken (Güncan, 1975, 1980; Kaya ve Zengin, 2000; Sirma 
ve Kadığlu, 2010). Orta ve Doğu Karadeniz Bölgesi'nde en sik rastlanan yabanc1 otlar Agrostemma githago L., Caucalis latifolia L., Ranunculus arvensis L., Galium tricornotum Dandy, Alopecurus myosuroides Huds, Avena spp., Polygonum aviculare L., Chenopodium album L., Convolvulus arvensis L., Adonis spp., Polygonum aviculare L., Sinapis arvensis L., Bifora radians Bieb. olarak belirtilmiştir (Mennan, 1993; Sırma, 1995; Sırma ve Güncan, 1997; Mennan ve Işık, 2003; Önen ve ark., 2012; Sirr1, 2014). Orta Anadolu Bölgesi'nde (Ankara, Yozgat, Eskişehir ve Konya) buğday ekim alanlarında baskın olan türlerin; Bifora radians Bieb., Galium tricornutum Dandy., Sinapis arvensis L., Alopecurus myosuroides Huds, Centaurea deprassa Bieb. (Taştan ve Erçiş, 1994; Karaca, 2010; Söker ve ark., 2012; Sırrı, 2014) olduğu saptanmıştır. Ege Bölgesi'nde buğday ekim alanlarında rastlanan dominant türlerin ise; Matricaria chamonilla L., Papaver rhoeas L., Raphanus raphanistrum L., Avena spp., Anagallis arvensis L., Capsella bursapostoris (L.) Medik., Lolium perene L., Polygonum aviculare L., Chenopodium album L. ve Convolvulus arvensis L. olduğu rapor edilmiştir (Boz, 2000; Boz ve ark., 2000). Dolayısıyla tür çeşitliliği, yoğunluğu, rastlama sıklığı ve dominat türler vb yönüyle Siirt ilinde yapılan survey sonuçları ile Türkiye'nin farklı bölgelerinde yapılan çalışmalar arasında görülen bu farklılıkların; iklim, topografya, tarım sistemi vb nedenlerden kaynaklandığı sonucuna varılmıştır. Bu kapsamda Ahmad ve Shaikh (2003), Baghestani ve ark. (2006), Gupta ve ark. (2008) Siddiqui ve ark. (2010) ve Hassannejad ve Ghafari (2013) tarafından yapılan çalışmalara ilişkin sonuçlar da çalışma sonuçlarımızı destekler niteliktedir.

Survey çalışmaları sonucunda genel olarak benzer yabanc1 ot türlerinin il genelinde dominant konumda bulunduğu görülmektedir. Bununla birlikte yabancı otların yaygınlı ve yoğunluklarının dolayısıyla da dominant türlerin ilçeler düzeyinde kısmen de olsa farklılık gösterdiği saptanmıştır (Tablo 2). Literatürde aynı bölgede yer alan iller veya ilin farklı ekolojik özelliklere sahip

Tablo 2. İlçeler bazında rastlama sıklıkları en yüksek olan yabancı ot türleri

\begin{tabular}{|c|c|c|c|c|c|c|c|}
\hline Bitkiler & Merkez & Kurtalan & Eruh & Pervari & Şirvan & Tillo & Baykan \\
\hline Aegilop scylindria Host. & & & & & & $\checkmark$ & \\
\hline Agrostis stolonifera L. & $\checkmark$ & & & & & & $\checkmark$ \\
\hline Ammi visnaga (L.) Lam. & & & $\checkmark$ & & & & \\
\hline Anagallis arvensis L. & $\checkmark$ & & & $\checkmark$ & & & $\checkmark$ \\
\hline Anchusa azurea Miller. & & & & $\checkmark$ & & & \\
\hline Anthemis arvensis L. & $\checkmark$ & $\checkmark$ & & & $\checkmark$ & & $\checkmark$ \\
\hline Aristolochia maurorum L. & $\checkmark$ & & & & & & \\
\hline Avena spp. & $\checkmark$ & $\checkmark$ & $\checkmark$ & $\checkmark$ & $\checkmark$ & $\checkmark$ & $\checkmark$ \\
\hline Bromus tectorum $\mathrm{L}$. & $\checkmark$ & $\checkmark$ & & & & & $\checkmark$ \\
\hline Bupleurum rotundifolium L. & & & $\checkmark$ & & & & \\
\hline Cardaria draba (L.) Desv. & & $\checkmark$ & $\checkmark$ & & & $\checkmark$ & \\
\hline Centaurea iberica Trevirex Sprengel. & & $\checkmark$ & & & & $\checkmark$ & \\
\hline Centaurea depressa Bieb. & & & $\checkmark$ & & & & \\
\hline Convolvulus arvensis L. & $\checkmark$ & $\checkmark$ & $\checkmark$ & & $\checkmark$ & $\checkmark$ & $\checkmark$ \\
\hline Erodium hoefftianum C.A.Mey & & & $\checkmark$ & & & & \\
\hline Fumaria officinalis L. & $\checkmark$ & & & & & & \\
\hline Galium aparine $\mathrm{L}$. & $\checkmark$ & $\checkmark$ & $\checkmark$ & & & $\checkmark$ & \\
\hline Hordeum murinum L. & $\checkmark$ & $\checkmark$ & & & & & $\checkmark$ \\
\hline Hordeum sp. & & $\checkmark$ & & & & & \\
\hline Linum spp. & & & $\checkmark$ & $\checkmark$ & & & \\
\hline Lisaea strigosa (Banksand sol.) Eig. & & $\checkmark$ & & $\checkmark$ & & & \\
\hline Lolium perenne L. & $\checkmark$ & & & & $\checkmark$ & $\checkmark$ & $\checkmark$ \\
\hline Medicago sativa L. & $\checkmark$ & & $\checkmark$ & & & & $\checkmark$ \\
\hline Papaver rhoeas L. & $\checkmark$ & $\checkmark$ & $\checkmark$ & $\checkmark$ & $\checkmark$ & $\checkmark$ & $\checkmark$ \\
\hline Phlaris bractystachys Link. & & & & & & & $\checkmark$ \\
\hline Picnomon acarna (L.) Cass. & & $\checkmark$ & & & & & \\
\hline Ranunculus arvensis L. & & & $\checkmark$ & & & & \\
\hline Silene conoidea L. & & & & $\checkmark$ & & & \\
\hline Silybum marianum (L.) Gaertner & $\checkmark$ & $\checkmark$ & & & & & $\checkmark$ \\
\hline Sinapis arvensis L. & $\checkmark$ & $\checkmark$ & $\checkmark$ & & $\checkmark$ & $\checkmark$ & $\checkmark$ \\
\hline Thlaspi arvense L. & & & $\checkmark$ & & & & \\
\hline Vaccaria pyramidata Medik & $\checkmark$ & $\checkmark$ & $\checkmark$ & $\checkmark$ & & & \\
\hline Veronica hederifolia L. & $\checkmark$ & & $\checkmark$ & & $\checkmark$ & & $\checkmark$ \\
\hline Vicia sativa $\mathrm{L}$. & $\checkmark$ & & $\checkmark$ & & $\checkmark$ & $\checkmark$ & \\
\hline
\end{tabular}


ilçeleri arasında dahi dominant türler yönüyle önemli farklılıkların olabildiği belirtilmektedir (Önen, 1995; Özer ve ark., 2001; Önen ve Özcan, 2010). Nitekim Güney Doğu Anadolu bölgesinde yer alan Diyarbakır ve Mardin illerinde sorun oluşturan türler arasında önemli farklılıklar bulunmaktadır (Gökalp ve Üremiş, 2015; Pala ve Mennan, 2017). Hatta aynı ilde farklı zaman aralıklarında yapılan survey verileri arasında dahi farklılıklar görülebilmektedir. Örneğin, Diyarbakır'da farklı dönemlerde yapılmış iki çalışmada buğday tarlalarında sorun olan yabancı otlar arasında farklılık bulunduğu saptanmıştır. Özaslan ve ark. (2011) tarafından Diyarbakır'da 2011 yılında yürütülen çalışmada en yaygın türlerin Avena streilis L., Cephalaria syriaca (L.) Schard, Sinapis arvensis L., Convolvulus arvensis L., Galium tricornutum Dandy., ve Lallemantia ibreica (Bieb) Fisch\&Mey olduğu belirtilirken; bundan 6 yıl sonra 2017 yılında yapılan bir çalışmada ise (Pala ve Mennan, 2017) yoğunluk oluşturan türlerin Avena fatua L., Sinapis arvensis L., Galium aperina L., Papaver rhoeas L. ve Cirsium arvense (L.) Scop olduğu rapor edilmiştir. Dolayısıyla yabancı ot türleri yere ve zamana göre büyük farkl1lıklar göstermektedir (Özer ve ark., 2001; Önen ve Özer 2001). Bu durum ilçeler arasında görülen farklılığ 1 açıklar niteliktedir. Yukarıda da değinildiği gibi bu farklılıkların ortaya çıkmasında iklim farklılıkları, toprak yapısı, rakım, bitki deseni, toprak işleme metotları, ekim alanı büyüklüğü, yabanc1 ot mücadele yöntemleri, ekonomik gelir seviyesi ve tohum temin yöntemleri gibi faktörlerin etkili olduğu (Uludağ, 1997; Önen ve Özer, 2001; Özer ve ark., 2001; Önen ve ark., 2012; Özgöz ve ark., 2012; Güncan, 2014 ve Tepe, 2014) kanısina varılmıştır.

\section{Sonuçlar}

Siirt ili için bir ilk niteliği taşıyan bu araştırmada elde edilen bulgular yabancı ot idare stratejilerinin geliştirilmesi yönüyle önem taşımaktadır. Bölgede survey sırasında yapılan gözlemler ve survey sonuçları yabancı otlarla başarılı bir şekilde mücadele yapılmadığını ortaya koymaktadır. Bölgenin ortalama buğday verim miktarının $216 \mathrm{~kg}$ $\mathrm{da}^{-1}$ Türkiye ortalamasının altında olması da bu durumu teyit eder niteliktedir. $\mathrm{Bu}$ nedenle birim alandan daha fazla ürün almak ve maliyetleri düşürmek için bölgede özellikle mono kültür uygulamalardan kaçınılması, bölge koşullarına uygun sertifikalı tohum kullanılması, sık ekim ve modern toprak işleme metotlarının uygulanması vb. işlemler yanında yabancı ot türleri, bunların etkileri ve kontrol yöntemleri hakkında çiftçilerin bilinçlendirilmesi için çalışmalara ihtiyaç duyulmaktadır.

\section{Kaynaklar}

Ahmad, R., Shaikh, A.S., 2003. Common weeds of wheat and their control. Pakistan Journal of Water Resources, 7(1): 73-76.

Anonim, 2018a. Bitkisel Üretim İstatistikleri. Türkiye İstatistik Kurumu (https://biruni.tuik.gov.tr/bitkisel app/bitkisel.zul), (Erişim tarihi: 05.05.2018).

Anonim, 2018b. Siirt İli İklim Verileri. Meteoroloji Genel Müdürlüğü (https://www.mgm.gov.tr), (Erişim tarihi: 11.07.2018).

Anonim, 2018c. Yabanc1 Otlar. Türkiye Herboloji Derneği (http://www.turkiyeherboloji.org.tr), (Erişim: 01.05. 2018).

Anonim, 2019. Bizimbitkiler org.tr (https://www.bizim bitkiler.org.tr/v2/turkce.php), (Erişim tarihi: 24.06.2019).

Anonymous, 2018. Statistical Data of FAOSTAT. (http://www.fao.org/faostat/en/\#home), (Erişim tarihi: 05.06.2018).

Baghestani, M.A., Zand, E., Soufzadeh, S., 2006. Iranian winter wheat's (Triticum aestivum L.) interference with weeds: I. Grain yield and competitive index. Pakistan Journal of Weed Science Research, 12(3): 119-129.

Baytop, A., 2007. Türkçe Bitki Adları Sözlüğü (3. Bask1). Atatürk kültür, dil ve tarih yüksek kurumu Türk dil kurumu yayınları: 578, Ankara.

Bilgir, S., 1965. Ege Bölgesi Hububat Tarlalarında Görülen Önemli Yabancı Otlar ve Savaş İmkanları Üzerinde Bazı İncelemeler. Tarım Bakanlığ Yayınları, Teknik Bülten, No: 14, İzmir.

Boz, Ö., 2000. Aydın ili buğday ekim alanlarında bulunan yabanc1 otlar ile rastlama siklıkları ve yoğunluklarının saptanması. Türkiye Herboloji Dergisi, 3(2): 1-11.

Boz, Ö., Doğan, M.N., Dura, S., 2000. Denizli ili buğday ekim alanlarındaki yabancı otların yaygınlık ve yoğunluklarının saptanması. Türkiye Herboloji Dergisi, 3(1): 37-52.

Davis, P.H., 1965-1989. Flora of Turkey and East Aegean Islands. Edinburg Univ. Press., Vol: 1-11, Edinburgh.

Gökalp, Ö., Üremiş, İ., 2015. Mardin buğday ekim alanlarında bulunan yabancı ot türlerinin, yaygınlıklarının ve yoğunluklarının belirlenmesi. Mustafa Kemal Üniversitesi Ziraat Fakültesi Dergisi, 20(1): 13-22.

Gupta, A., Joshi, S.P., Manhas, R.K., 2008. Multivariate analysis of diversity and composition of weed communities of wheat fields in Doon Valley. Tropical Ecology, 49(2): 103-112.

Güncan, A., 1975. Erzurum çevresinde bulunan yabanc1 otlar ve önemlilerinden bazılarının yazlık arpa ve buğdayda mücadele imkanları üzerinde araştırmalar. Atatürk Üniversitesi, Ziraat Fakültesi araştırma serisi no: 135, Erzurum, s. 51-55.

Güncan, A., 2001. Yabanc1 Otlar ve Mücadele Prensipleri. Selçuk Üniversitesi Ziraat Fakültesi Yayınları, (5. Bask1), Konya. 
Güncan, A., 2014. Yabanc1 Ot Mücadelesi. Selçuk Üniversitesi Yayınevi, (3. Bask1), Konya.

Güngör, M., 2005. Adana ili mısır ekim alanlarında yabanc1 otlara karşı uygulanan kimyasal mücadelenin önemi ve ortaya çıan sorunların araştırılması. Yüksek lisans tezi, Çukurova Üniversitesi, Fen Bilimleri Enstitüsü, Adana.

Hassannejad, S., Ghafarbi, S.P., 2013. Weed flora survey of Tabriz wheat (Triticum aestivum L.) fields. Journal of Biodiversity and Environmental Sciences, 3(6): 118-132.

Hurle, K., 1988. How to handle weeds? Biolojicaland Economic Aspects. Proceedings of the 4th European Ecology Symposium, 7-12 September, Netherlands, pp. 63-68.

İnan, İ.H., Rehber, E., 1987. Türkiye'de tahıl üretiminin ekonomik yapıs1 ve sorunları. Türkiye Tahıl Sempozyumu, 6-9 Ekim, Bursa, s. 665-673.

Karaca, M., 2010. Yatık Gökbaș (Centaurea depressa Bieb.) ve Kokarot (Bifora radians Bieb.)'un baz1 biyolojik özellikleri ve Konya yöresinde buğdayda ekonomik zarar eşiklerinin tespiti. Doktora tezi, Selçuk Üniversitesi Fen Bilimleri Enstitüsü, Konya.

Kaya, Y., Zengin, H., 2000. Pasinler Ovasındaki buğday tarlalarında sorun oluşturan yabancı otlarla, rastlama sıklıkları, hayat formları ve fitocoğrafik bölgelerinin belirlenmesi. Türkiye Herboloji Dergisi, 3(1): 17-26.

Kordali, Ş., Zengin, H., 2011. Bayburt yöresinde arpa ekim alanlarında görülen yabancı otlar, yoğunlukları, yaygınlıkları ve topluluk oluşturma durumları üzerinde çalışmalar. Atatürk Üniversitesi Ziraat Fakültesi Dergisi, 42(2): 117-131.

Mennan, H., 1993. Samsun ili buğday ekim alanlarında görülen yabanc1 ot türlerinin belirlenmesi ve önemli türlerin çimlenme ve gelişme biyolojilerinin araştırılması. Yüksek lisans tezi, Çukurova Üniversitesi Fen Bilimleri Enstitüsü, Adana.

Mennan, H., Iș1k, D., 2003. Buğday tohumluğunda bulunan yabanc1 ot tohumlarının yoğunlukları ve bitkiye dönüșüm oranlarının saptanması. Türkiye Herboloji Dergisi, 6(1): 8-15.

Odum, E.P., 1971. Fundamentals of Ecology 3rd Ed. W.B. Saunders Company, Philadelphia, pp. 574.

Önen, H., 1995. Tokat Kazova'da yetiştirilen şekerpancarında sorun olan yabancı otlar ile uygulanan farklı savaş yöntemlerinin verime olan etkileri üzerine araştırmalar. Yüksek lisans tezi, Gaziosmanpaşa Üniversitesi Fen Bilimleri Enstitüsü, Tokat.

Önen, H., Özer, Z., 2001. Tarla içerisinde yabancı otların dağılımları arasındaki farklılıkların haritalanarak belirlenmesi. Türkiye Herboloji Dergisi, 4(2): 74-83.

Önen, H., Özcan, S., 2010. İklim değişikliğine bağlı olarak yabancı ot mücadelesi. M. Sayılı (Ed.), iklim değişikliğinin tarıma etkileri ve alınabilecek önlemler. T.C. Kayseri Valiliği İl Tarım Müdürlüğü Yayın No: 2, Kayseri, s. 336-357.

Önen, H., Özgöz, E., Özer, Z., 1012. Toprak işleme yöntemlerinin buğdayda yabancı otlanmaya ve verime etkileri. Gaziosmanpasa Üniversitesi Ziraat Fakültesi Dergisi, 29(1): 99-104.

Önen, H., Akdeniz, M., Farooq, S., Hussain, M., Özaslan, C., 2018. Weed Flora of Citrus Orchards and Factors Affecting its Distribution in Western Mediterranean Region of Turkey. Planta Daninha, 36: e018172126.

Özaslan, C., Boyraz, N., Güncan, A., 2011. Diyarbakır ili buğday ekim alanlarında sorun olan yabancı otların belirlenmesi. Türkiye IV. Bitki Koruma Kongresi Bildirileri, 28-30 Haziran, Kahramanmaraş s. 139.

Özer, Z., Önen, H., Uygur, N.F., Koch, W., 1996. Farklı Kültürlerde Sorun Olan Yabancı Otlar ve Kimyasal Savaşımları. Gaziosmanpaşa Üniversitesi, Ziraat Fakültesi Yayınları, No: 15, Kitap Serisi: 8, Tokat.

Özer, Z., Tursun, N., Önen, H., Uygur, F.N., Erol, D., 1998. Herbaryum Yapma Teknikleri ve Yabanc1 Ot Teşhis Yöntemleri. Gaziosmanpaşa Üniversitesi, Ziraat Fakültesi Yayınları, No: 12, Tokat.

Özer, Z., Önen, H., Tursun, N., Uygur, F.N., 1999. Türkiye'nin Bazı Önemli Yabanc1 Otları. Gaziosmanpasa Üniversitesi, Ziraat Fakültesi Yayınları, No: 38, Kitap Seri No: 16, Tokat.

Özer, Z., Kadığlu, İ., Önen, H., Tursun, N., 2001 Herboloji (Yabanc1 Ot Bilimi). Gaziosmanpaşa Üniversitesi Ziraat Fakültesi Yayınları, No: 20 Kitap Seri No: 10, Tokat.

Özgöz, E., Günal, H., Önen, H., Bayram, M., Acir, N., 2012. Effect of management on spatial and temporal distribution of soil physical properties. Journal of Agricultural Sciences, 18(1): 77-91.

Özrenk, K., Tepe, I., 1999. A Study on Determining Pathogenic Rust Fungi on Weeds in Van Province. Türkiye Herboloji Dergisi, 2(1): 17-24.

Özyazıc1, M.A., Dengiz, O., İmamoğlu, A., 2014. Siirt ili bazı arazi ve toprak özelliklerinin coğrafi bilgi sistem analizleriyle değerlendirilmesi. Türkiye Tarımsal Araştırmalar Dergisi, 1(2): 128-137.

Pala, F., Mennan, H., 2017. Diyarbakır buğday tarlalarında bulunan yabancı otların belirlenmesi. Bitki Koruma Bülteni, 57(4): 447-461.

Siddiqui, I., Bajwa, R., Huma, Z.E., Javaid, A., 2010. Effect of six problematic weeds on growth and yield of wheat. Pakistan Journal of Botany, 42(4): 24612471.

Sirma, M., 1995. Tokat yöresinde buğday alanlarında sorun olușturan yabanc1 otlar, önemlilerinden bazılarının topluluk oluşturma durumları ve topraktan kaldırdıkları "N,P,K" miktarı özerinde bir arastırma. Doktora tezi, Selçuk Üniversitesi Fen Bilimleri Enstitüsü, Konya.

Sırma, M., Güncan, A., 1997. Tokat yöresinde buğday ekim alanlarında sorun oluşturan yabancı otlar ve önemlilerinden bazılarının topluluk oluşturma durumları üzerine bir araştırma. Türkiye II. Herboloji Kongresi, 1-4 Eylül, İzmir, s. 289-304.

Sirma, M., Kadığlu, İ., 2010. Erzincan ili Otlubeylik ilçesi buğday ekim alanlarında saptanan önemli yabancı ot türleri, rastlama sıklıkları ve yoğunlukları. Gaziosman Paşa Üniversitesi Ziraat Fakültesi Dergisi, 27(1): 27-34. 
Sirrı, M., 2014. Tokat (Kazova) ve Konya (Çumra) ovalarında arazi kullanımına bağlı olarak yabancı ot dağılımının belirlenmesi. Yüksek lisans tezi, Gaziosmanpaşa Üniversitesi Fen Bilimleri Enstitüsü, Tokat.

Söker, A., Koyuncu, O., Yaylacı, Ö.K., Tokur, S., 2012. Weed flora in some agricultural fields of Eskișehir and environs. Artvin Çoruh Üniversitesi Orman Fakültesi Dergisi, 13(1): 109-127.

Taştan, B., Erciş, A., 1991. Orta Anadolu Bölgesi buğday ekim alanlarında gözlenen yabancı otların yayılış ve yoğunlukları üzerinde araştırmalar. Bitki Koruma Bülteni, 31(1-4): 39-60.

Tepe, I., 1998. Van'da buğday ürününe karıșan yabanc1 ot tohumlarının yoğunluk ve dağılımları. Türkiye Herboloji Dergisi, 1(2): 1-13.

Tepe, I., 2014. Yabancı Otlarla Mücadele. Sidas Medya Ziraat Yayın No: 031, İzmir.

Tursun, N., Kantarc1, Z., Seyithanoğlu, M., 2004 Adıyaman ve Gaziantep bölgelerinde buğday ürününe karışan yabancı ot tohumlarının belirlenmesi. Türkiye Herboloji Dergisi, 7(1): 1-12.
Uludağ, A., 1997. Weed infestation level changes in cereal in Diyarbakır, Turkey. 10th EWRS Symposium, 22-26 June, Poland, pp. 22.

Uludağ, A., Katkat. M., 1993. Güneydoğu Anadolu Bölgesinde meyve fidanlıklarında bulunan yabancı otlar ve yoğunluklarının belirlenmesi üzerinde çalıșmalar. Türkiye I. Herboloji Kongresi, 3-5 Şubat, Adana, s. 175-184.

Uluğ, E., Kadıŏglu, İ., Üremiş, İ., 1993. Türkiye'nin Yabancı Otları ve Bazı Özellikleri. T.C Tarım ve Köyişleri Bakanlığı. Adana Zirai Mücadele Araştırma Enstitüsü, Yayın No: 78, Adana.

Uygur, F.N., Kadıoğlu, İ., Boz, Ö., Mennan, H., 1999. Yabancı otların ekonomik zarar eșiği ve dünya ile Türkiye'deki uygulamaları. Bitki Korumada Ekonomik Zarar Eșiği Modelleri ve Uygulamas Workshop'u Bildirileri, 8-9 Eylül, Samsun, s. 170225.

Whitehead, R., Wright, H.C., 1989. The Incidence of weeds in winter Cereal in Great Britain. Brighten Crop Protection Conference-Weeds, 20-23 November, England, pp. 107-112. 